\title{
A Study on "Internet Buzzwords" as Popular Culture: Characteristics, Existing Problems and Suggestions
}

\author{
Jing Luo $^{1, *}$ \\ ${ }^{1}$ School of Literature, The Capital Normal University, BeiJing, China \\ *596860020@qq.com
}

\begin{abstract}
On the basis of modern computer and network technology, "Internet buzzwords" have gradually moved from "inside the network" to "outside the network". As one of the important forms of popular culture, it has the trend of wider and wider influence, faster and faster spread and wider popularity. The syntactic combination forms of Internet buzzwords are different, covering rich and diverse contents, which maps out some features such as the discourse revelry of deconstructing elitism, the coexistence of popularity and interest, exist side by side of the easy duplication and anticlassicality, and humanistic care in power resistance. At the same time, the network world is mixed with good and bad together, which will inevitably lead to some problems. How to strengthen its own standard development is particularly important for contemporary China, which is becoming a cultural power day by day, especially for tapping the zeitgeist of Internet buzzwords, to pay attention to it from the perspective of cultural studies.
\end{abstract}

Keywords: popular culture, Internet buzzwords, characteristics, existing problems, suggestions

\section{INTRODUCTION}

In the early 20th century, people's knowledge of popular culture was mostly obtained from cultural commodities such as "advertising art, film and television culture, costume culture, street art, network culture", especially some classic songs and popular stories. In the late 20th century, domestic scholars focused on nonWestern cultural studies, trying to find a new research perspective, and there was a craze for cultural studies. After the reform and opening-up, the computer network has gradually become popular, and the network culture has emerged as the times require. It is based on the latest scientific and technological achievements of mankind, the Internet and mobile phones as carriers, relying on the developed and rapid information transmission system, using certain language symbols, sound symbols, visual symbols, etc., to spread ideas, cultures, customs and people's feelings, express opinions, vent emotional awareness and so on. ${ }^{[1]}$

In the Understanding Popular Culture, John Fiske said: "The essence of popular culture is that it is invincible. Although capitalism is nearly a hundred years old, the dominant subculture has always existed, and never compromise to resist the final collection, those who hold subcultures have been 'plotting new ways to rip their own jeans.' It shows that behind the entertainment characteristics of popular culture also implies the deconstruction of elite culture, in order to acquiring the fighting characteristics of discourse power."[2] This shows that Internet buzzwords which belong to the special form of popular cultural, as a feast of discourse carnival, coupled with its different historical era and historical development, is eliminating the hierarchical characteristics of the mass group of Internet users.

\section{THE CHARACTERISTICS OF THE "INTERNET BUZZWORDS" AS POPULAR CULTURE}

\subsection{Popularization and interest coexist}

Internet buzzwords are a carnival, in which netizens can express their wishes and demands. It reflects a certain degree of public opinion. In this case, Internet buzzwords also become a isotopic carrier. For example, "Yuanfang Style" became popular on the Internet. The phrase "Yuan Fang, what do you think of this matter" was nicknamed "Yuanfang Style" by netizens. It originated from $\mathrm{Li}$ Yuanfang's answer in the TV series "Detective Di Renjie". When judging difficult cases, Di Renjie always asks his assistant Li Yuanfang's opinion using the sentence "Yuan Fang, what do you think of this matter". Li Yuanfang replied: "My Lord, there must be something 
strange about this matter, and there must be a shocking conspiracy behind it." Then an online incident of Quanzhou girl jumping off a building made the catchwords become popular in society with lightning speed. After the police intervened in the investigation, it was found that it was suicide. But the netizens felt that it was not so simple. They suspected that there was something behind the case, so they used this incident as a gimmick to get to the bottom of it and mocked it with "Yuan Fang, what do you think of this matter?" In the process of using it, in order to express a questioning, mocking or uncertain attitude and viewpoint about something or someone, people are used to putting it at the end of a sentence or paragraph to quote it, so as to enhance the language potential and better express their feelings.

\subsection{Reproducibility and anti-classic peer}

The cultural characteristics of Internet buzzwords, such as easy copying and anti-classicality, are mainly manifested in two aspects: the patterning and batch production. Network hot post "You have to be careful if you get caught talking about qq, You Mu You!!!Squeeze into biscuits to and from work, You Mu You!!!” It is a typical "roaring genre". The "Roaring Genre Style" comes from Douban.com. There is no special fixed format or content in it, but it contains two key words: "can't afford to hurt" and "You Mu You". One of its major features is that every sentence must end with an exclamation. When the user is in high spirits, one or two exclamation marks can't fully express his strong feelings. The more exclamation marks are used, the stronger visual effect will be, which will make people feel immersive and bursting out. "You Mu You" plays an important role in "Roaring Genre Style", which generally appears in online communities and is a kind of online community culture. Some "Roaring Genre Style" have neat formats and look very beautiful, which attract many netizens' attention, such as:

\section{Don't want to go to work, You Mu You!!!}

Don’t want to get up, You Mu You! !!

Don't want to take the exam, You Mu You!!!

Applying this format in this way, the "Roaring Genre Style" represented by "You $\mathrm{Mu}$ You" expresses a nonmainstream or self-deprecating or teasing or angry emotion of netizens, to be precise, it is a manifestation of emotional catharsis.

\subsection{Humanistic care in resistance to power}

In 2008, "Don't abandon, don't give up" was deeply imprinted in the national mind. This sentence comes from "Soldiers' Assault" which is a series of TV plays. It brings people full of positive energy, and they would rather sacrifice themselves than give up their comrades- in-arms. This is a great spiritual force, and it is this spiritual force that spreads the fine traditions and national spirit of Chinese people all over China through this condensed online hot word. Especially in the front line of earthquake resistance in Sichuan in 2008, Premier Jiabao Wen, when faced with natural disasters, took no pains and firmly encouraged the victims to have a spirit of "Don't abandon, don't give up" to fear the lives of themselves and others. So far, this sentence full of positive energy has spread all over China, inspiring the confidence of the Chinese nation in overcoming difficulties. "Taobao Style" with the word "qin" is widely used in all aspects of life. A traffic safety sign erected on the streets of Xingtai, Hebei Province: "Qin, don't run a red light!" Compared with the daily use of "No running red lights", it is more close to the people. In fact, it uses a more acceptable and popular way to express the same information. Another example is the Internet buzzword "you can't afford to hurt". It is also a manifestation of self-emotional fragility and emotional sensitivity. It is often used to imply that I can no longer withstand the damage caused by wind and waves and others. Here, the image of successful people, as the myth of half face, magnifies one aspect of reality, but covers the other, and their lifestyle releases the impulse of contemporary people to pursue fame and fortune. Therefore, it has become what the public yearns for and is liked by the public. The poetic dispelling in daily life is that countless netizens growl "I can't afford to hurt".

\section{PROBLEMS EXISTING AS "INTERNET BUZZWORDS" OF POPULAR CULTURE}

\subsection{From the perspective of concept definition: it is easy to be confused with "buzzwords"}

"'Network language' at first mostly refers to computer language of the network, and also refers to natural language with its own characteristics used on the network." ${ }^{[3]}$ It includes two meanings: First, it refers to terms and vocabulary related to Internet and computer technology and application; Second, it is the language that people use to communicate and express through computer and Internet media. Undoubtedly, network language refers to the language form at the macro level, while network buzzwords use the network as the medium. Unlike buzzwords, network language is a language that is popular on the Internet, recognized by netizens and widely spread. It can be said that the two languages are both different and interrelated, just as most scholars think that "Internet buzzwords" have the general characteristics of "network language" conciseness, humor and randomness, and at the same time, they are more popular, novel and available. Internet buzzwords are the crystallization of the wisdom of the masses. They truly record the changes of the society and the world Vientiane 
in the process of communication, and are a direct and effective way for us to know the network and even the society. Nowadays, the Internet buzzwords are constantly emerging and changing, spreading more faster and wider, and exerting greater influence on people's daily life ${ }^{[4]}$. Internet buzzwords are gradually moving from "inside the network" to "outside the network", becoming the mantra of people's life, and finally evolving into social buzzwords to spread in a certain period of time.

\subsection{From the perspective of word formation: the grammatical function is destroyed}

Looking at the Internet buzzwords in recent years, from the form of words, there are several ways such as "homophonic words" "digital meanings" "out of context" "English-Chinese combination" and "single word into words". Homonyms such as "Yali (pressure)" "I'm too south (difficult)" "Weibo (twitter)" "blue and thin, mushrooms (uncomfortable, want to cry)" "prawn (Great Xia, the meaning of network master)" and so on. Digital meanings include "996 (9: 00 a.m., 9: 00 p.m., 6 days a week)" "1314 (lifetime)" and so on. Take it out of context, such as "embarrassed chat" "can't afford to hurt" "official announcement" and "lemon essence"etc. EnglishChinese combinations such as"打 call (support)" “xx style" “大 V(Microblog users with a large number of fans)" and so on. Single word into words like “亲 (dear)" “怼 (against)” “圆 (embarrassed)”and“赞 (praise)”etc. Some of these buzzwords break down normal Chinese characters, re-collage and combine them, breaking the original norms and customary grammatical rules of the Chinese system, such as "Bai Gujing" is a combination of white-collar workers, backbones and elites, etc., which will inevitably lead to problems such as improper collocation, inverted word order, meaning-seeking, ambiguous expression and so on, and some try to express them based on the principle of simplicity and clarity.All these different ways are affecting the social communication effect of language.

\subsection{From the perspective of communication: it is easy to bring obstacles to intergenerational communication}

In 2009, "Jia Junpeng, your mother told you to go home for dinner"; in 2011, "I can't afford to hurt"; in 2014, "Meng Meng Da"; in 2017, "Xi Jing"; in 2018, "Gang jing"and in 2019,"Ningmeng jing". All these Internet buzzwords spread among different groups of netizens. For example, the word "you know" comes from the famous forums of Tianya and Maopu. This is an industry lingo dedicated to the seizure of an unhealthy incident in 2008, which was immediately ridiculed by the majority of netizens. It is another funny reaction of the wisdom of the masses to network control. Now it is often used to express the intimate and tacit privacy among young people. It's hard to say that the online buzzwords like "Your mother told you to go home for dinner" have any specific or other significance, but this warm humor, which is in contrast with reality, has unique charm. With the acceleration of the pace of life in modern society, for adults, the old days are gradually drifting away, and it has become a beautiful memory worth recalling. This warmth is also the reason why this buzzword born from online games has vitality. In 2014, "Does your family know" was spread by a netizen who watched the news broadcast in an Internet cafe said, "You are so awesome here, does your family know?" Then, according to word of mouth, "Does your family know"soon became popular in the network communication circle. The development potential and scalability of this sentence also brought countless inspiration to netizens. These Internet buzzwords all come from specific social events or popular games of that year, and are made by quoting typical words in events or classic lines in games. As for the communication between two generations, because of the great differences in their thoughts, environments and behaviors, it is obvious that children or young people are better at using the Internet as a medium, and the frequency of using Internet buzzwords is higher than that of parents.

\section{SUGGESTIONS ON THE NORMS OF "INTERNET BUZZWORDS" AS POPULAR CULTURE}

\subsection{Constantly strengthen the internal theoretical feasibility study of Internet buzzwords}

The theoretical basis for the development of Internet buzzwords is reflected in two aspects. The first is the distinction between popular culture theory and Antonio Gramsci's culture theory in the definition of "hegemony". ${ }^{[5]}$ One view is represented by Frankfurt School, holds that popular culture is the manipulator of ideology, with strong control, and is a kind of culture imposed by capitalist cultural industry. Another view is represented by traditional British culturalism, holds that popular culture is a kind of working class culture, a voice from the bottom of society and a culture that naturally emerges from the bottom of society. ${ }^{[6]}$ The production and popularity of Internet buzzwords can be regarded as the culture produced when the masses automatically consume in practice, which meets the needs of the development of social network culture. The second is the adaptability of Gramsci's hegemony theory to the study of network culture. Gramsci's hegemonic theory of popular culture has exerted a wide influence in 1970s and 1980s. Popular culture is no longer the ideology of bourgeois propaganda of Frankfurt School. It is both acceptance and obedience, and also is confrontation. It is a paradox with conflicts and continuous development. 
Popular buzzwords pay attention to the pleasure of production, and it will inevitably have a considerable impact on the social culture at that time from top to bottom. For example, in 2012, “Are you XingFu (happy)? My last name is not Fu, my last name is Zeng", and then the topic of "happiness" caused a sensation and aroused heated discussion. Are there really many happy people? Does this mean that people's inner happiness has really increased? Now there are still quite a few people who can only express their "unhappiness" by saying "my last name is Zeng". For the people at the bottom of life, if happiness can be spoken from them, it must be true happiness.

\subsection{Affirm people's value and strengthen humanistic care}

As a popular culture, the "Internet buzzwords" spread from certain social events or news, criticizing the shortcomings and being full of human concern when laughing and cursing, and it can be more popular and resonate, which is also the psychological basis of becoming a buzzword. The core of humanistic care lies in affirming human nature, which is the affirmation of human value. This word originated from western humanism is full of the brilliance of human nature. In the traditional communication context, because there are few channels to express opinions, vulnerable groups are relatively short of the right to speak, but they often suffer from anxiety and worry caused by life. The popularity of the Internet has effectively found a solution to this problem. Today, in the rapid development of the "digital age", with the media as an intermediary, Internet buzzwords, a new carrier, is becoming a part of popular culture and gradually entered people's lives. With this, a kind of "language" with special referential significance has been formed, such as "ant tribe" "neet tribe" "short and poor people" "Beijing drifter" "the secondgeneration rich"and "leftover lady", which often reflect many deep-seated social problems in reality. On the one hand, they make fun of these problems concisely, on the other hand, they also play a great role in attracting the attention of managers or the media. How to make the public feel the power of being cared for in their daily life urgently needs to be put on the agenda.

\subsection{Based on the Internet, firmly grasp the great opportunity in the information age}

According to the 48th Statistical Report on Internet Development in China, as of June 2021, the number of Internet users in China has reached 1.011 billion, the Internet penetration rate has reached $71.6 \%$, the average online time of Internet users in China is 26.9 hours per week, the total number of mobile phone base stations has reached 9.48 million, the digital basic services have become increasingly abundant, the total ratio of fiber broadband users has increased to $94 \%$, the development scale of $5 \mathrm{G}$ ranks first in the world, and the industrial Internet platform system has basically taken shape. ${ }^{[7]}$ In the process of social language and culture development in China, Internet buzzwords are widely used and popular by netizens with the help of network media. However, when some network languages are applied to daily life, some people can't understand the meaning of the words or sentences because they violate the language development law of modern Chinese itself, which limits the development of Internet buzzwords to a certain extent, and also has an adverse impact on the standardization of modern Chinese vocabulary. Therefore, the prevalence of Internet buzzwords is both an opportunity and a challenge for the further standardization and development. In this diversified network environment, we should selectively sublate it. We should have a tolerant attitude towards Internet buzzwords such as give timely and correct guidance to its negative effects, so as to promote the healthy development of popular culture.

\section{CONCLUSIONS}

As is known to all that the network language are changing with each passing day. The Internet buzzwords is Just like a mirror of social development, which will be passed down or die out with the test of practice, inherited or transformed. From the above analysis, we know that behind its rapid spread, on the one hand, there are unique cultural characteristics of Internet buzzwords as popular culture; on the other hand, there will inevitably be some problems with the mixed network world. In the computer era, people are more inclined to use media, WeChat, hot words, buzzwords and blogs. As a part of the network culture, Internet buzzwords not only reflects the public's concern for the people's livelihood, but also represents the wisdom, thought and strength of netizens. Therefore, how to strengthen its own normative development from the perspective of cultural studies is particularly necessary for contemporary China, which is becoming a cultural power.

\section{REFERENCES}

[1] Yungong Yin, On Network Culture, News and Writing, No.5, 2007.

[2] John Fiske, Understanding Popular Culture, Central Compilation Press, 2006.

[3] Genyuan Yu, An Overview of Network Language, China Economic Publishing House, 2001, p. 2.

[4] Gang Luo, Xiangyu Liu, Cultural Studies Reader, China Social Sciences Press, 2000.

[5] Antonio Gramsci, Selections from the Prison Notebooks, Henan University Press, 2014.

[6] Max Horkheimer and Theodor W. Adorno, Dialectic of Enlightenment, Edited by Gunzelin Schmid Noerr, Translated by Edmund Jephcott, Stanford University Press, 2002.

[7] http://www.cnnic.net.cn/hlwfzyj/hlwxzbg/hlwtjbg/2 02109/t20210915 71543.htm 